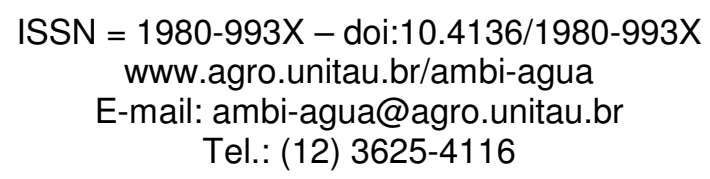

\title{
Avaliação da qualidade da água superficial dos cursos de água do município de Pelotas-RS, Brasil (doi:10.4136/ambi-agua.85)
}

\author{
Paulo Carteri Coradi ${ }^{1}$; Ronaldo Fia ${ }^{1}$; Orlando Pereira-Ramirez ${ }^{2}$ \\ ${ }^{1}$ Universidade Federal de Viçosa - UFV \\ E-mail: paulocoradi@yahoo.com.br; ronaldo.fia@ufv.br \\ ${ }^{2}$ Universidade Federal de Pelotas - UFPel \\ E-mail: orlando@ufpel.edu.br
}

\section{RESUMO}

O presente trabalho foi realizado no município de Pelotas-RS, e teve por objetivo avaliar a qualidade das águas, entre os anos de 1996 e 1998, nos principais cursos de água que cortam o município, utilizando-se o Índice de Qualidade de Água de Bascarán (IQA $\mathrm{I}_{\mathrm{b}}$ ). Verificou-se que a qualidade dos corpos de água avaliados foi aceitável, com exceção da Barragem da Eclusa e da Barragem Santa Bárbara, que apresentaram como poluente mais impactante o fósforo. Durante o período de estiagem prolongado, entre os anos de 1996 e 1997, houve redução nos valores do $\mathrm{IQA}_{\mathrm{b}}$. Além disso, o índice refletiu a realidade ambiental verificada na região, devido à agricultura intensiva e ao lançamento de grande parte dos efluentes domésticos e industriais sem prévio tratamento nos mananciais.

Palavras-chave: Índice de Qualidade de Água; Arroio Pelotas; Canal São Gonçalo; monitoramento de rios.

\section{Evaluation of surface water quality in waterways located in the municipality of Pelotas, RS, Brazil}

\begin{abstract}
The present work was performed in the municipality of Pelotas, RS, Brazil with the objective of evaluating water quality from the years of 1996 to 1998, in the principal waterways which pass through the municipality using the Water Quality Index of Bascarán $\left(\mathrm{IQA}_{\mathrm{b}}\right)$. It was verified that the water quality in the evaluated bodies was acceptable with the exception of the Eclusa and Santa Bárbara reservoirs, in which phosphorus is the most important pollutant. During the period of prolonged drought from 1996 to 1997, there was a reduction in the IQA $\mathrm{A}_{\mathrm{b}}$. The index also reflected the environmental status verified in the region due to intensive agriculture and the release of a large portion of domestic and industrial wastes to the waterways without previous treatment.
\end{abstract}

Keywords: Water Quality Index; Arroio Pelotas; São Gonçalo canal; river monitoring.

\section{INTRODUÇÃO}

As águas doces superficiais existentes, passíveis de serem utilizadas pelo homem de forma economicamente viável e sem grandes impactos ao meio ambiente, correspondem somente $0,001 \%$ da água do planeta. Apesar de serem um recurso extremamente escasso, os recursos hídricos disponíveis no globo são hoje suficientes para atender às necessidades de todos os seres humanos. Contudo, o problema da escassez da água está relacionado, dentre outras questões, à desigual distribuição entre as diversas regiões e à poluição e à contaminação dos recursos naturais (REBOUÇAS, 1999). No Brasil, apesar da distribuição 
CORADI, P. C.; FIA, R., PEREIRA-RAMIREZ, O. Avaliação da qualidade da água superficial dos cursos de água do município de Pelotas-RS, Brasil. Ambi-Agua, Taubaté, v. 4, n. 2, p. 46-56, 2009. (doi:10.4136/ambiagua.85)

irregular em algumas regiões, o principal problema está relacionado à poluição das águas superficiais e subterrâneas.

Em decorrência de sua importância, tanto em relação a seus diversos usos quanto à manutenção de sua qualidade e quantidade, os recursos hídricos são considerados bens comuns, que devem ser geridos de forma integrada, garantindo o aproveitamento com o mínimo de conflito, e fazendo dos recursos hídricos uma questão não só ecológica como também política, econômica e social (Calijuri e Bubel, 2006).

A qualidade da água é resultante de fenômenos naturais e de ações antrópicas, em função do uso e ocupação do solo na bacia hidrográfica. A interferência do homem é uma das maiores causas de alteração da qualidade da água, seja por meio de uma forma concentrada, com a geração de efluentes domésticos ou industriais, ou de uma forma dispersa, com aplicação de insumos agrícolas e manejo inadequado do solo, contribuindo para a incorporação de compostos orgânicos e inorgânicos nos cursos de água e alterando diretamente sua qualidade.

A caracterização da qualidade da água é uma das formas de se avaliar os impactos causados pela interferência humana em sistemas aquáticos, possibilitando seu manejo de forma mais adequada e, até mesmo, a sua remedição. $\mathrm{O}$ acompanhamento do estado dos recursos hídricos é de fundamental importância, pois é pela poluição que são introduzidas substâncias nocivas, tóxicas ou patogênicas que modificam as características físicas, químicas e biológicas do meio ambiente aquático. Uma forma de se monitorar a qualidade das águas é por meio de índices, denominados Índices de Qualidade de Água (IQA). Em geral, o IQA é um número adimensional que exprime a qualidade da água para os diversos usos. Esse número é obtido da agregação de dados físicos, químicos e bacteriológicos, por meio de metodologias específicas.

Dentre os IQAs, destacam-se o índice adaptado para as condições brasileiras pela Companhia de Tecnologia de Saneamento Ambiental do Estado de São Paulo (CETESB), os Índices de Prati, Dinius, McDuffie e Horton, sendo os últimos utilizados em menor escala no Brasil (Brasil, 2004).

Outro importante índice é o Índice de Qualidade da Água de Bascarán (IQA $\mathrm{I}_{\mathrm{b}}$, que proporciona um valor global de qualidade da água, incorporando valores individuais de uma série de variáveis (Bascarán, 1979 apud Rizzi, 2001). O IQA bastante flexível, pois permite a introdução ou exclusão de variáveis de acordo com as necessidades ou limitações para obtenção de dados, sendo possível definir um índice básico com um número reduzido de variáveis e outro completo com maior número de variáveis (Rizzi, 2001).

Muitos IQAs foram desenvolvidos e têm sido utilizados em todo mundo para várias formas de avaliação. A escolha do índice a ser usado dependerá das fontes poluidoras existentes no local e do uso pretendido para o curso de água em questão, além da possibilidade de realização das análises das variáveis utilizadas. Vale ressaltar que todos os índices apresentam um grau de subjetividade, pois seus resultados dependerão da escolha das variáveis que constituirão os indicadores das alterações da qualidade das águas em determinada situação.

Diante do exposto, o objetivo deste trabalho foi avaliar a qualidade das águas dos principais recursos hídricos da cidade de Pelotas-RS, entre os anos de 1996 e 1998, utilizando-se o Índice de Qualidade de Água de Bascarán (IQA $)$.

\section{MATERIAL E MÉTODOS}

A cidade de Pelotas está localizada na região sudeste do estado do Rio Grande do Sul,

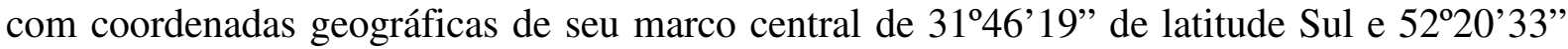


CORADI, P. C.; FIA, R., PEREIRA-RAMIREZ, O. Avaliação da qualidade da água superficial dos cursos de água do município de Pelotas-RS, Brasil. Ambi-Agua, Taubaté, v. 4, n. 2, p. 46-56, 2009. (doi:10.4136/ambiagua.85)

de longitude Oeste, e a uma distância de $250 \mathrm{~km}$ da cidade de Porto Alegre. O município de Pelotas possui pouco mais de 300.000 habitantes e está situado às margens do Canal São Gonçalo, que liga as lagoas dos Patos e Mirim. Os arroios Pepino, Santa Bárbara e Pelotas deságuam no Canal São Gonçalo e provém deles a maior parte da água destinada ao abastecimento humano da cidade de Pelotas (SANEP, 2009).

Entre os corpos de água que se localizam no município de Pelotas, foram selecionados seis pontos para coleta de amostras e determinação da qualidade da água: Arroio Pelotas, Arroio Pepino, Barragem do Arroio Santa Bárbara, Canal São Gonçalo, Barragem da Eclusa e Porto (Figura 1). Nesses pontos foram coletadas manualmente duas amostras mensais entre os anos de 1996 e 1998, exceto para o Arroio Pepino e a Barragem Santa Bárbara nos quais se coletaram amostras de água apenas no ano de 1996. Para analisar a qualidade da água, determinaram-se as concentrações de oxigênio dissolvido (OD); demanda bioquímica de oxigênio (DBO); sólidos dissolvidos totais (SDT); $\mathrm{pH}$; fósforo total $(\mathrm{P})$; nitrogênio amoniacal $\left(\mathrm{N}_{\mathrm{Am}}\right)$, nitrato $\left(\mathrm{NO}_{3}{ }^{-}\right)$, alcalinidade total $(\mathrm{AT})$, cloretos $\left(\mathrm{Cl}^{-}\right)$, gás carbônico livre $\left(\mathrm{CO}_{2}\right)$ e temperatura da água.

As análises foram realizadas no Laboratório de Controle de Poluição do DCTA, da Faculdade de Agronomia Eliseu Maciel, na Universidade Federal de Pelotas (UFPel), seguindo a metodologia apresentada em APHA (1995).

Devido a ausência de dados na maioria das coletas, os valores de $\mathrm{IQA}_{\mathrm{b}}$ calculados neste trabalho não levaram em consideração a contaminação microbiológica, mas somente as variáveis monitoradas durante toda a campanha amostral.

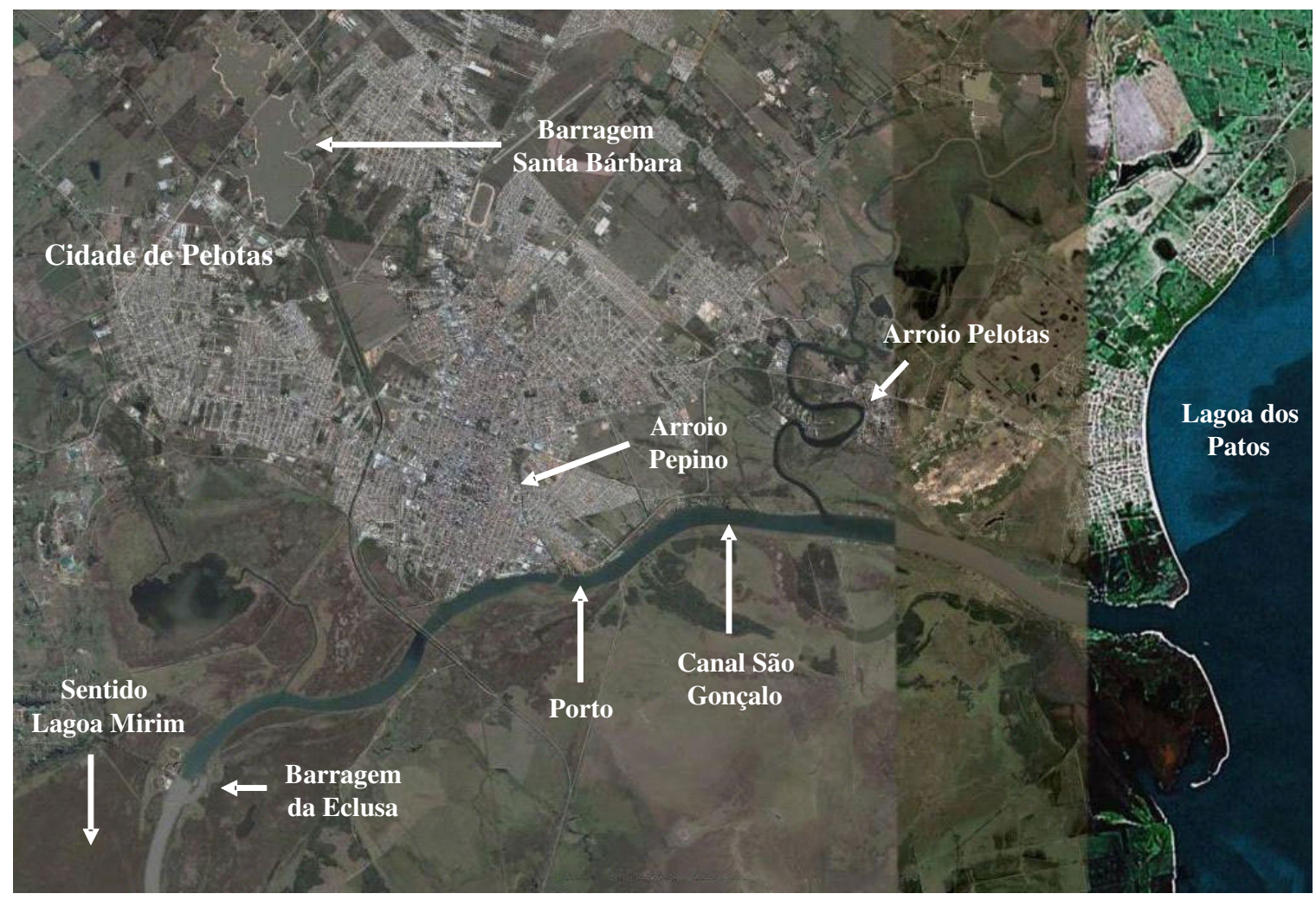

Figura 1. Vista parcial da cidade de Pelotas-RS, e dos principais cursos de água do município (adaptado de: Google Earth, 2009).

A partir das variáveis determinadas, fez-se a média mensal dos resultados e calculou-se o Índice de Qualidade de Água de Bascarán (IQA $)$ (Bascarán, 1979 apud Rizzi, 2001), adaptando-o às variáveis avaliadas. $\mathrm{O} \mathrm{IQA}_{\mathrm{b}}$ foi calculado utilizando-se a Equação 1: 
CORADI, P. C.; FIA, R., PEREIRA-RAMIREZ, O. Avaliação da qualidade da água superficial dos cursos de água do município de Pelotas-RS, Brasil. Ambi-Agua, Taubaté, v. 4, n. 2, p. 46-56, 2009. (doi:10.4136/ambiagua.85)

$$
I Q A_{b}=K \times \frac{\sum C_{i} \times P_{i}}{\sum P_{i}}
$$

$\mathrm{C}_{\mathrm{i}}=$ valor percentual correspondente à variável (tabelado);

$\mathrm{P}_{\mathrm{i}}=$ peso correspondente a cada variável (tabelado); e

$\mathrm{K}=$ constante de ajuste em função do aspecto visual das águas (1,00 para águas claras; 0,75 para águas com ligeira cor, espuma e turbidez não natural; 0,50 para águas contaminadas e com forte odor; 0,25 para águas que apresentam fermentações e odores). Neste trabalho o valor de K adotado foi 0,75 .

$\mathrm{O}$ valor de $\mathrm{IQA}_{\mathrm{b}}$ varia de zero a 100 e corresponde a uma escala qualitativa de caracterização que varia desde o aspecto péssimo ao excelente (Tabela 1).

Tabela 1. Aspecto aparente de qualidade da água em função do valor de $\mathrm{IQA}_{\mathrm{b}}$ calculado.

\begin{tabular}{lclc}
\hline Aspecto aparente & Valor do $\mathbf{I Q A}_{\mathbf{b}}$ & Aspecto aparente & Valor do $\mathbf{~ I Q A}_{\mathbf{b}}$ \\
\hline Péssimo & 0 & Aceitável & 60 \\
Muito ruim & 10 & Agradável & 70 \\
Ruim & 20 & Bom & 80 \\
Desagradável & 30 & Muito bom & 90 \\
Impróprio & 40 & Excelente & 100 \\
Normal & 50 & & \\
\hline
\end{tabular}

\section{RESULTADOS E DISCUSSÃO}

Na Tabela 2 estão apresentados os valores máximos, mínimos e médios, bem como o desvio padrão dos resultados das análises físicas e químicas, realizadas nas amostras coletadas ao longo do período de monitoramento dos cursos de água que cortam a cidade de Pelotas.

A temperatura da água refletiu as variações correspondentes às estações ao longo do ano em que ocorreram as amostragens, variando entre $9,9^{\circ} \mathrm{C}$ no inverno e $32,8^{\circ} \mathrm{C}$ no verão, ambas no porto da cidade.

Os valores de $\mathrm{pH}$ medidos nas amostras coletadas variaram entre 5,4 e 8,2, e os valores médios permaneceram próximos a 7,0, não afetando a vida aquática. Embora não seja o único, o pH de sistemas aquáticos é um importante indicador de qualidade da água e a extensão da poluição em cursos de água. Corpos hídricos não poluídos geralmente apresentam uma variação nos valores de $\mathrm{pH}$ próximo da neutralidade. $\mathrm{O} \mathrm{pH}$ altera a solubilidade e, por isso, a disponibilidade de muitas substâncias, mas também afeta a toxicidade de substâncias como os metais e formas disponíveis de nitrogênio. Segundo a Resolução CONAMA n 357 de 2005, para manutenção da vida aquática, o pH deve situar-se entre 6,0 e 9,0 (Brasil, 2005b).

Os valores médios de alcalinidade encontrados em grande parte dos corpos de água avaliados foram inferiores a $50 \mathrm{mg} \mathrm{L}^{-1}$ de $\mathrm{CaCO}_{3}$, caracterizando essas águas como águas "moles" ou "brandas". No entanto, amostras pontuais coletadas na Barragem Santa Bárbara apresentaram valores de alcalinidade superiores a $50 \mathrm{mg} \mathrm{L}^{-1} \mathrm{de} \mathrm{CaCO}_{3}$, caracterizando-o como um curso de água com dureza moderada (Macêdo, 2004). Águas com alcalinidade elevada, além de apresentarem gosto desagradável, podem causar algum desconforto após a sua ingestão, devido a sua ação laxativa. O calcário utilizado como corretivo de solo disponibiliza carbonatos e bicarbonatos, que estão diretamente relacionados à alcalinidade das águas. Além disso, o lançamento de esgotos tende a aumentar os valores de alcalinidade nos cursos de água, como observado por Ceretta (2004).

A presença de cloreto $\left(\mathrm{Cl}^{-}\right)$foi maior nas amostras coletadas no Arroio Pelotas, no canal São Gonçalo e na Barragem da Eclusa. Os valores médios encontrados nesses três corpos de 
CORADI, P. C.; FIA, R., PEREIRA-RAMIREZ, O. Avaliação da qualidade da água superficial dos cursos de água do município de Pelotas-RS, Brasil. Ambi-Agua, Taubaté, v. 4, n. 2, p. 46-56, 2009. (doi:10.4136/ambiagua.85)

água foram superiores aos limites recomendados pelo Ministério da Saúde para ingestão humana que é de $250 \mathrm{mg} \mathrm{L}^{-1}$ (Brasil, 2005a). Em meio natural, o cloreto é oriundo da dissolução de minerais ou mesmo da intrusão de água marinha, além de ser proveniente dos despejos de efluentes domésticos e industriais, e de águas utilizadas na irrigação de lavouras (von Sperling, 2005). Vale destacar que os maiores valores médios encontrados nos três cursos de água foram influenciados pelos maiores valores obtidos durante duas épocas de estiagem prolongada, compreendendo os períodos de abril a julho de 1996 e janeiro a julho de 1997 (EMBRAPA, 2009), favorecendo a concentração do cloreto. O efeito da estiagem prolongada, durante o ano de 1996, também refletiu no aumento das concentrações de cloreto no Arroio Pepino e na Barragem Santa Bárbara, entre os meses de abril e julho.

Tabela 2. Valores máximos, mínimos, médios e desvio padrão das variáveis físicas e químicas obtidas durante os três anos de monitoramento dos corpos de água da cidade de Pelotas.

\begin{tabular}{|c|c|c|c|c|c|c|c|c|c|c|c|c|}
\hline \multirow{2}{*}{$\begin{array}{c}\text { Corpo } \\
\text { hídrico }\end{array}$} & & & 1 & AT & $\mathrm{Cl}^{-}$ & $\mathbf{P}$ & $\mathrm{NO}_{3}^{-}$ & $\mathbf{N}_{\mathrm{AM}}$ & $\mathrm{CO}_{2}$ & OD & DBO & SDT \\
\hline & & pH & $\left({ }^{\circ} \mathrm{C}\right)$ & \multicolumn{9}{|c|}{$\left(\mathrm{mg} \mathrm{L}^{-1}\right)$} \\
\hline \multirow{4}{*}{$\begin{array}{l}\text { Arroio } \\
\text { Pelotas }\end{array}$} & Max & 7,7 & 27,0 & 49,6 & $3.478,0$ & 28,1 & 6,2 & 1,2 & 10,0 & 10,2 & 8,0 & $6.612,0$ \\
\hline & Min & 6,5 & 10,2 & 23,4 & 7,9 & 0,2 & ND & ND & 0,4 & 5,5 & 1,1 & 84,0 \\
\hline & Med & 7,0 & 19,3 & 32,4 & 424,6 & 3,7 & 1,2 & 0,6 & 5,6 & 7,3 & 2,2 & 912,1 \\
\hline & DP & 0,3 & 4,3 & 5,6 & 925,8 & 8,1 & 1,6 & 0,3 & 2,0 & 1,1 & 1,2 & $1.709,5$ \\
\hline \multirow{4}{*}{$\begin{array}{l}\text { Barragem } \\
\text { da Eclusa }\end{array}$} & &, 5 & 26,0 & 42,5 & 56,7 & 31,5 & 6,2 & 7,4 & 10,2 & 10,6 & 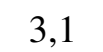 & $5.112,3$ \\
\hline & Min & 5,4 & 11,0 & 19,7 & 6,7 & ND & ND & 0,0 & ND & 0,0 & 0,1 & 83,7 \\
\hline & Med & 7,0 & 19,3 & 29,9 & 331,2 & 5,4 & 1,1 & 2,8 & 2,7 & 5,8 & 1,3 & 815,7 \\
\hline & $\mathrm{DP}$ & 0,4 & 4,2 & 5,2 & 759,7 & 8,2 & 1,7 & 3,2 & 2,5 & 3,4 & 0,9 & $1.521,0$ \\
\hline \multirow{4}{*}{$\begin{array}{c}\text { Canal São } \\
\text { Gonçalo }\end{array}$} & Max & 7,7 & 26,8 & 46,7 & $3.906,2$ & 40,5 & 6,3 & 2,6 & 10,0 & 10,5 & 3,0 & $7.349,3$ \\
\hline & Min & 6,4 & 10,0 & 20,0 & 8,1 & 0,1 & ND & ND & 0,4 & 5,7 & 0, & 80,0 \\
\hline & Med & 6,9 & 18,8 & 30,6 & 520,3 & 4,6 & 1,3 & 0,3 & 5,4 & 7,6 & 1,8 & $1.164,8$ \\
\hline & DP & 0,3 & 4,4 & 6,4 & 998,5 & 10,8 & 1,7 & 0,5 & 2,3 & 1,1 & 0,6 & $2.008,0$ \\
\hline \multirow{4}{*}{$\begin{array}{l}\text { Arroio } \\
\text { Pepino }\end{array}$} & & J, & 24,8 & 48 & 651,4 & 41 & & 1,7 & 8,7 & 9,3 & 6 & $1.354,2$ \\
\hline & Min & 6,9 & 10,3 & 32,8 & 14,6 & 0 & ND & ND & 1,2 & 5,8 & 0 , & 187,0 \\
\hline & Med & 7,2 & 19,0 & 40,2 & 133,1 & 17 & 2, & 0,5 & 5,4 & 7,6 & 3 , & 428,8 \\
\hline & DP & 0,2 & 5,0 & 4,8 & 214,3 & 18,1 & 2,8 & 0,7 & 2,2 & 1,1 & 1,6 & 398,5 \\
\hline \multirow{4}{*}{$\begin{array}{l}\text { Barragem } \\
\text { Santa } \\
\text { Bárbara }\end{array}$} & Max & 7,5 & 25,2 & 68,2 & 437,8 & 43,6 & 7,6 & 4,2 & 18,0 & 8,0 & 12,7 & $1.099,8$ \\
\hline & Min & 6,8 & 10,1 & 30,0 & 14,4 & 0,6 & ND & ND & 0,8 & 4,6 & 0,9 & 142,5 \\
\hline & Med & 7,2 & 19,1 & 46,3 & 84,4 & 16,3 & 2,9 & 0,8 & 9,1 & 6,2 & 3,7 & 367,9 \\
\hline & DP & 0,2 & 5,1 & 12,1 & 142,1 & 15,2 & 2,7 & 1,4 & 5,7 & 1,1 & 4,0 & 314,7 \\
\hline \multirow{4}{*}{ Porto } & Max & 8,2 & 32,8 & 43,2 & 26,1 & 39,0 & 1,1 & 0,6 & 4,5 & 11,0 & 7,0 & 262,5 \\
\hline & Min & 6,6 & 9,9 & 24,0 & 9,4 & 0,1 & ND & ND & 1,3 & 7,4 & 0,0 & 86,0 \\
\hline & Med & 7,5 & 19,3 & 32,6 & 15,1 & 4,7 & 0,6 & 0,1 & 2,9 & 8,8 & 2,3 & 145,4 \\
\hline & DP & 0,3 & 5,4 & 5,2 & 3,1 & 8,9 & 0,3 & 0,2 & 0,8 & 1,0 & 1,0 & 44,4 \\
\hline
\end{tabular}

$\mathrm{T}$ - Temperatura da água; $\mathrm{AT}$ - Alcalinidade total; $\mathrm{Cl}^{-}$- Cloreto; $\mathrm{P}$ - Fósforo; $\mathrm{NO}_{3}{ }^{-}-\mathrm{Nitrato} ; \mathrm{N}_{\mathrm{AM}}-\mathrm{Nitrogênio}$ amoniacal; $\mathrm{CO}_{2}$ - Dióxido de carbono; OD - Oxigênio dissolvido; DBO - Demanda bioquímica de oxigênio; SDT Sólidos dissolvidos totais; Max - máximo; Min - mínimo; Med - média; DP - desvio-padrão; e ND - não detectado.

As concentrações de nitrato $\left(\mathrm{NO}_{3}{ }^{-}\right)$e nitrogênio amoniacal $\left(\mathrm{N}_{\mathrm{AM}}\right)$ foram relativamente baixas, principalmente para a segunda forma de nitrogênio. Assim, pode-se considerar que os cursos de água avaliados apresentam boa capacidade de reaeração das águas, exceto na 
CORADI, P. C.; FIA, R., PEREIRA-RAMIREZ, O. Avaliação da qualidade da água superficial dos cursos de água do município de Pelotas-RS, Brasil. Ambi-Agua, Taubaté, v. 4, n. 2, p. 46-56, 2009. (doi:10.4136/ambiagua.85)

Barragem da Eclusa e na Barragem Santa Bárbara, onde predomina ambiente lêntico. Nesses pontos de amostragem, a concentração de nitrogênio amoniacal superou a concentração estabelecida para cursos de água em condição Classe 2 que é de $3,7 \mathrm{mg} \mathrm{L}^{-1}$, para valores de pH inferiores ou iguais a 7,5 (Brasil, 2005b). Elevadas concentrações de nitrogênio associadas às de fósforo podem vir a causar desenvolvimento exagerado do fito e zooplâncton, levando ao processo de eutrofização.

As concentrações de fósforo nas amostras foram elevadas podendo tornar esses cursos de água eutrofizados, pois o fósforo é essencial para o crescimento de organismos e pode ser o nutriente que limita a produtividade primária de um corpo de água. Dessa forma, esse elemento tem sido apontado como o principal fator responsável pela eutrofização dos sistemas aquáticos (Esteves, 1998). Os valores médios obtidos superaram as concentrações limites estabelecidas pelo CONAMA (Brasil, 2005b), para cursos de água em condição Classe 3, de $0,05 \mathrm{mg} \mathrm{L}^{-1}$ para ambientes lênticos a $0,15 \mathrm{mg} \mathrm{L}^{-1}$ para ambientes lóticos.

Em todos os corpos de água, os valores médios de DBO foram inferiores a $3,7 \mathrm{mg} \mathrm{L}^{-1}$, sendo os maiores valores médios encontrados na Barragem Santa Bárbara e no Arroio Pepino. Os valores de DBO indicam a extensão da poluição orgânica em sistemas aquáticos, os quais afetam negativamente a qualidade das águas. As reduzidas quantidades de matéria orgânica biodegradável refletidas pelas concentrações de DBO apresentadas pelos cursos de água, favoreceram a manutenção dos valores de oxigênio dissolvido elevados. A concentração de oxigênio dissolvido nas amostras coletadas, exceto para a Barragem da Eclusa, é considerada satisfatória para manutenção de vida aeróbia, sendo o menor valor pontual encontrado de 4,6 $\mathrm{mg} \mathrm{L}^{-1}$ na Barragem Santa Bárbara.

Apesar do valor médio encontrado para o oxigênio dissolvido na Barragem da Eclusa ser satisfatório $\left(5,8 \mathrm{mg} \mathrm{L}^{-1}\right)$; nesse ponto foram verificados valores de oxigênio dissolvido mínimos (1,3 $\left.\mathrm{mg} \mathrm{L}^{-1}\right)$ durante toda a campanha de amostragem de 1998, chegando à concentração de $0,0 \mathrm{mg} \mathrm{L}^{-1}$ em dezembro do mesmo ano. Nessa condição, não há possibilidade de sobrevivência de organismos aeróbios, podendo ser considerada condição anóxica. Durante toda campanha de 1998, notou-se, também, valores mínimos de DBO e consequentemente de matéria orgânica biodegradável, uma das principais causadoras da redução de oxigênio dissolvido no meio aquático. Dessa forma, acredita-se que a oxidação de compostos inorgânicos como, por exemplo, o nitrogênio amoniacal, tenha favorecido a redução do oxigênio no meio (von Sperling, 2005). Considerando a Barragem da Eclusa como um ambiente lêntico e, também, a elevada concentração de fósforo nas águas, poderia se esperar que houvesse um maior desenvolvimento de algas (eutrofização) e, consequentemente, uma maior produção de oxigênio no meio, por esses organismos.

As menores concentrações de matéria orgânica biodegradável também mantiveram os valores de dióxido de carbono próximos a $10 \mathrm{mg} \mathrm{L}^{-1}$ (Bascarán, 1979 apud Rizzi, 2001), podendo ser considerado normal para cursos de água superficiais. Com pouca matéria orgânica não há decomposição microbiana ou esta se encontra em reduzida escala, emitindo menores quantidades de $\mathrm{CO}_{2}$ no meio líquido. Além disso, se a água for rica em carbonatos (maior alcalinidade) oriundos principalmente das calagens de solos, como sucede com as águas que percorrem regiões produtoras de arroz próximas a Pelotas, o gás carbônico se combina a esses sais, transformando-os em bicarbonatos, os quais formam uma solução tampão, com maior capacidade de manter um quadro mediano dos valores de $\mathrm{pH}$ (Macêdo, 2004), como observado neste trabalho. Exceção pode ser feita às concentrações de gás carbônico encontradas na Barragem Santa Bárbara, cujos valores na maioria das amostragens foram superiores a $10 \mathrm{mg} \mathrm{L}^{-1}$ como observado por Piedras et al. (2006) nos afluentes da Barragem Santa Bárbara. Nesse curso de água, a alcalinidade também foi superior àquelas encontradas nos demais cursos de água. Assim, acredita-se que as concentrações de gás carbônico poderiam ser maiores, e só não foram devido à reação com o carbonato presente. 
CORADI, P. C.; FIA, R., PEREIRA-RAMIREZ, O. Avaliação da qualidade da água superficial dos cursos de água do município de Pelotas-RS, Brasil. Ambi-Agua, Taubaté, v. 4, n. 2, p. 46-56, 2009. (doi:10.4136/ambiagua.85)

A presença de sólidos dissolvidos na água indica a presença de sais, ácidos minerais e outros contaminantes similares despejados nos cursos de água. Elevadas concentrações de sólidos dissolvidos podem aumentar a demanda química e bioquímica de oxigênio nas águas, levando à depleção do oxigênio dissolvido no meio, além disso, os sólidos dissolvidos podem refletir a carga de poluentes lançadas no curso de água. A concentração média de sólidos dissolvidos ficou próxima a $150 \mathrm{mg} \mathrm{L}^{-1}$ nas amostras coletadas no porto. No entanto, as concentrações de sólidos dissolvidos obtidas nas demais amostras foram entre duas e cinco vezes superiores àquelas encontradas nesse nesse ponto amostral. Semelhante ao observado para as concentrações de cloreto, as concentrações médias de sólidos totais dissolvidos obtidas nas amostras coletadas no Canal São Gonçalo, no Arroio Pelotas e Barragem da Eclusa foram influenciadas pelos maiores valores obtidos durante duas épocas de estiagem prolongada, compreendendo os períodos de abril a julho de 1996 e janeiro a julho de 1997; as amostras da Barragem Santa Bárbara e do Arroio Pepino também foram influenciadas pela estiagem no ano de 1996. (EMBRAPA, 2009). Assim, acredita-se que os íons cloreto possam ter sido os maiores contribuidores para as maiores concentrações de sólidos dissolvidos obtidos nesse período de monitoramento.

As amostras coletadas no Canal São Gonçalo, no Arroio Pelotas e na Barragem da Eclusa apresentaram valores médios de sólidos dissolvidos totais superiores a $500 \mathrm{mg} \mathrm{L}^{-1}$, ultrapassando o limite para condição Classe 2 nos corpos de água.

Na Figura 2, estão apresentados os valores de IQA $A_{b}$ obtidos com a análise das amostras coletadas nos cursos de água, enquanto na Tabela 3, são apresentados os valores médios mensais obtidos durante os três anos de monitoramento. Pode-se verificar que não houve amostragem no mês de junho de 1998.

Os resultados obtidos para os seis cursos de água amostrados variaram ao longo dos três anos de acompanhamento. No entanto, de forma geral, apresentaram as mesmas tendências. Os valores de $\mathrm{IQA}_{\mathrm{b}}$ variaram entre 33 e 71.

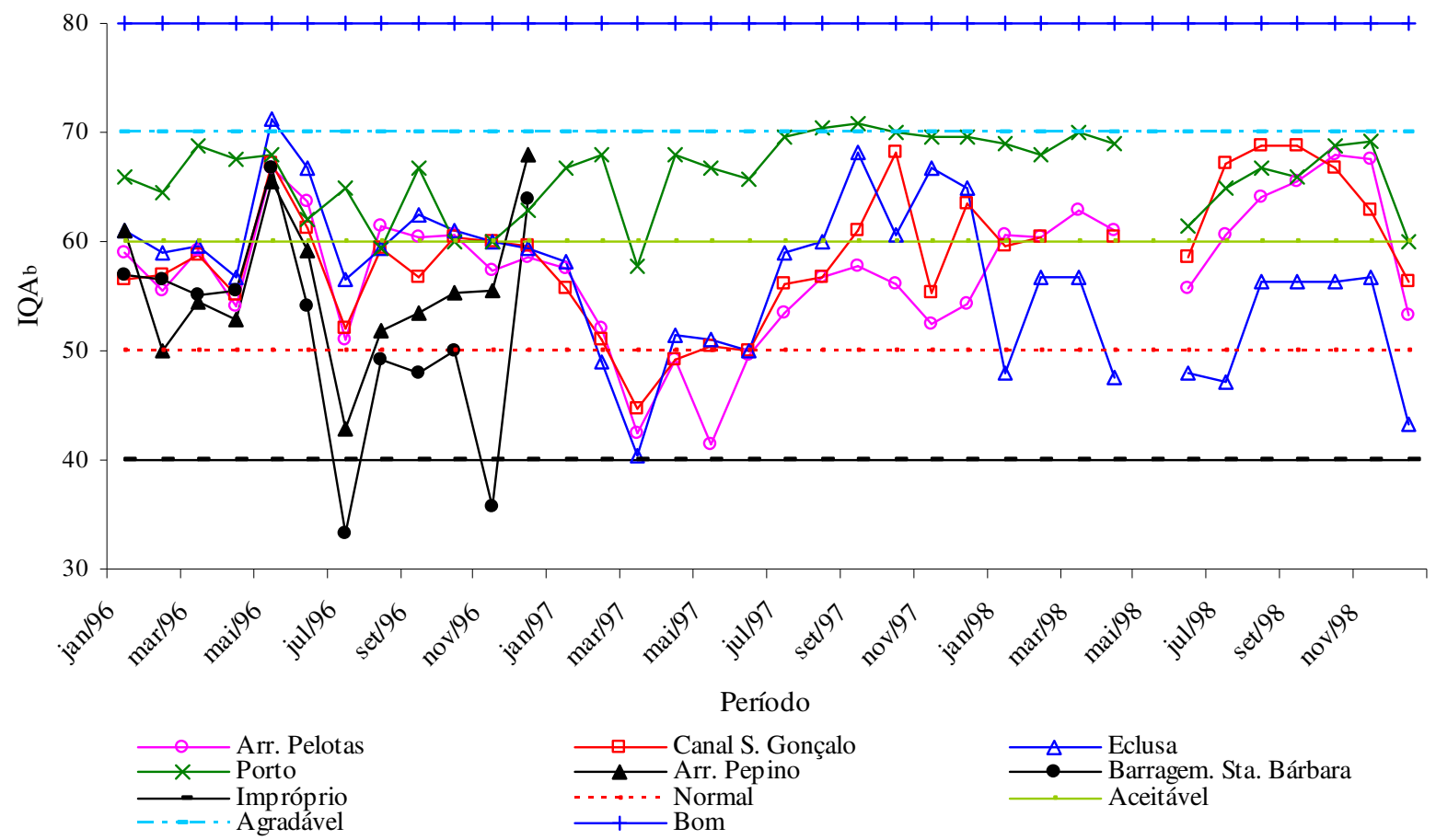

Figura 2. Valores dos IQA $A_{b}$ obtidos na avaliação de corpos de água influenciados pela cidade de Pelotas-RS.

Os menores valores de IQA $\mathrm{I}_{\mathrm{b}}$ obtidos na Barragem Santa Bárbara e no Arroio Pepino, no mês de julho de 1996, foi coincidente com o período extremo da estiagem. De forma 
CORADI, P. C.; FIA, R., PEREIRA-RAMIREZ, O. Avaliação da qualidade da água superficial dos cursos de água do município de Pelotas-RS, Brasil. Ambi-Agua, Taubaté, v. 4, n. 2, p. 46-56, 2009. (doi:10.4136/ambiagua.85)

semelhante, no Canal São Gonçalo, na Barragem da Eclusa e no Arroio Pelotas, os menores valores de IQA $\mathrm{I}_{\mathrm{b}}$ obtidos entre os meses de fevereiro e junho de 2007, foram influenciados em maior parte pelo acréscimo nas concentrações de cloretos e sólidos dissolvidos totais, em consequência também da redução nos valores de oxigênio dissolvido obtidos no mesmo período. Nos meses em que se observou redução nos índices de qualidade de água, verificouse também redução no índice pluviométrico na região e, consequentemente, redução nas vazões (Brum et al., 2005; EMBRAPA, 2009). Durante o ano de 1998, as amostras coletadas na Barragem da Eclusa apresentaram valores de IQA ${ }_{b}$ reduzidos justificados pela redução dos valores de oxigênio dissolvido nas águas desse ponto amostral.

Tabela 3. Valores dos IQA $\mathrm{A}_{\mathrm{b}}$ médios mensais obtidos durante o período de monitoramento dos cursos de água.

\begin{tabular}{lcccccccccccc}
\hline \multicolumn{1}{c}{ Cursos de água } & Jan & Fev & Mar & Abr & Mai & Jun & Jul & Ago & Set & Out & Nov & Dez \\
\hline Arr. Pelotas & 59 & 56 & 55 & 55 & 54 & 56 & 55 & 61 & 61 & 62 & 59 & 55 \\
Canal S. Gonçalo & 57 & 56 & 52 & 55 & 59 & 57 & 58 & 62 & 62 & 65 & 59 & 60 \\
Eclusa & 56 & 55 & 52 & 52 & 61 & 55 & 54 & 59 & 62 & 59 & 61 & 56 \\
Arr. Pepino & 61 & 50 & 55 & 53 & 65 & 59 & 43 & 52 & 54 & 55 & 56 & 68 \\
Barragem Sta. Bárbara & 57 & 57 & 55 & 55 & 67 & 54 & 33 & 49 & 48 & 50 & 36 & 64 \\
Porto & 67 & 67 & 66 & 68 & 67 & 63 & 67 & 65 & 68 & 66 & 66 & 64 \\
\hline
\end{tabular}

$\mathrm{O}$ aumento dos valores de $\mathrm{IQA}_{\mathrm{b}}$ durante o período de ocorrência das chuvas pode ser atribuído, provavelmente, ao efeito diluição que ocorreu em função do aumento da vazão dos cursos de água e a consequente redução na concentração de contaminantes, tal como observado por Molina et al. (2006). Fato contrário foi observado por Silva et al. (2006), o qual encontrou menores valores de oxigênio dissolvido nos meses chuvosos comparados aos demais meses. Os autores justificaram o fato, devido ao aumento dos sólidos em suspensão e da turbidez, além do aumento da matéria orgânica no ecossistema aquático que, para sua decomposição microbiana, consome grande parte ou a totalidade do oxigênio dissolvido. A baixa taxa de fotossintética do fitoplâncton associada à redução da transparência do meio aquático devido aos sólidos em suspensão também está relacionada à redução do oxigênio dissolvido.

Diante dos resultados, pode-se considerar que os cursos de água avaliados apresentaram características satisfatórias quanto à qualidade das águas, exceto para a Barragem Santa Bárbara, nos meses de julho e novembro de 1996, e para a Barragem da Eclusa que, mesmo em um período sem anomalias climáticas como o período de estiagem ocorrido em 2007, continuou com reduzidos valores de IQA $\mathrm{b}_{\mathrm{b}}$. No entanto, outros trabalhos têm demonstrado elevado nível de contaminação nas águas do Canal São Gonçalo (Grützmacher et al., 2008) e no Arroio Pelotas (Leal et al., 2008), além da reduzida concentração de oxigênio dissolvido nas águas da Barragem Santa Bárbara (Piedras et al., 2006).

$\mathrm{O}$ aporte de material orgânico e inorgânico nos cursos de água ocorre por dois motivos principais: efluentes urbanos da cidade de Pelotas, e o carreamento de material originado das áreas agrícolas. Nessas bacias hidrográficas, entre 95 e $98 \%$ do uso consultivo das águas superficiais é decorrente da irrigação, principalmente da cultura do arroz (Rio Grande Do Sul, 2008).

A entrada de material originado das áreas agrícolas e de fontes urbanas contribui para o aumento na carga de fósforo, amônia e sólidos dissolvidos, além de promover o decréscimo na concentração de oxigênio dissolvido, devido ao consumo deste elemento nos processos respiratórios da comunidade aquática, principalmente se for material orgânico biodegradável. 
No entanto, apesar do aumento da concentração de nutrientes nos corpos de água e decréscimo nas concentrações de oxigênio dissolvido, não foi verificado o aumento nos valores de DBO.

Como reflexo da falta de manejo adequado do solo nas áreas rurais, principalmente, pela retirada da cobertura vegetal que protege os solos da erosão laminar, do cultivo intensivo do solo (Prefeitura Municipal de Pelotas, 2006), e da ausência de saneamento básico com o lançamento in natura de esgotos nos mananciais, pode-se verificar que o IQA $\mathrm{A}_{\mathrm{b}}$ médio reflete o elevado conteúdo de partículas e matéria inorgânica que são lançadas nesses cursos de água. Atualmente, a cidade de Pelotas conta com rede coletora de esgotos que atende a $67 \%$ da população urbana, com predomínio no perímetro central da cidade. De todo o esgoto coletado cerca de $40 \%$ apenas recebe tratamento (SANEP, 2009).

Diante dos resultados obtidos, verifica-se elevada concentração de fósforo nas águas, além de maiores quantidades de nitrato quando comparadas às de amônio. No entanto, a matéria orgânica, expressa em termos de DBO, apresentou valores reduzidos. Assim, em função dessa combinação de fatores, acredita-se que as maiores formas de contribuição para poluição dos cursos de água avaliados foram às contribuições de formas inorgânicas de poluição, advindas, principalmente, da atividade industrial, agrícola e portuária.

\section{CONCLUSÕES}

Pode-se concluir que:

- A qualidade hídrica dos cursos de água avaliados que cortam o município de Pelotas foi, no geral, aceitável, com exceção da Barragem da Eclusa e da Barragem Santa Bárbara;

- Os valores de IQA $\mathrm{A}_{\mathrm{b}}$ variaram entre 33 e 71, durante o período de monitoramento;

- O poluente mais impactante na obtenção dos valores de IQA $A_{b}$ em todos os cursos de água avaliados foi o fósforo;

- Os resultados obtidos demonstraram a redução pontual nos valores do IQA $A_{b}$ durante períodos extensos de estiagem.

\section{REFERÊNCIAS}

\section{AMERICAN PUBLIC HEALTH ASSOCIATION - APHA. Standard methods for the examination of water and wastewater. 19. ed. Washington: APHA/AWWA/WEF, 1995.}

BRASIL. Ministério da Saúde. Secretaria de Vigilânica em Saúde. Coordenação-Geral de Vigilância em Saúde Ambiental. Portaria MS n. 518/2004. Brasília: Ministério da Saúde, 2005a. 28 p. (Série E. Legislação em Saúde)

Ministério do Meio Ambiente. Conselho Nacional de Meio Ambiente - CONAMA. Resolução no 357 - Dispõe sobre a classificação dos corpos de água e diretrizes ambientais para o seu enquadramento, bem como estabelece as condições e padrões de lançamento de efluentes. Brasília: MMA, 2005b.

Ministério do Meio Ambiente. Programa Nacional do Meio Ambiente II - Seleção de índices e indicadores. Brasília: MMA, 2004. Disponível em: $<$ http://www.cprh.pe.gov.br/downloads/indice-agua-volume1.pdf $>$. Acesso em: 20 agosto 2008. 
CORADI, P. C.; FIA, R., PEREIRA-RAMIREZ, O. Avaliação da qualidade da água superficial dos cursos de água do município de Pelotas-RS, Brasil. Ambi-Agua, Taubaté, v. 4, n. 2, p. 46-56, 2009. (doi:10.4136/ambiagua.85)

BRUM, D. R.; KUNZE, I. G.; FIGUEIREDO, E. L.; FOSTER P. R. Estudo da variabilidade dos elementos meteorológicos na cidade de Pelotas - RS. In: CONGRESSO DE INICIAÇÃO CIENTÍFICA, 14., 2005. Pelotas. Anais... Pelotas: UFPel, 2005. Disponível em: <http://www.ufpel.edu.br/cic/2005/arquivos/CE_01181.rtf.>. Acesso em: 10 agosto 2008 .

CALIJURI, M. C.; BUBEL, A. P. M. Conceituação de microbacias. In: LIMA, W. P.; ZAKIA, M. J. B. (Orgs.). As florestas plantadas e a água: implementando o conceito de microbacia hidrográfica como unidade de planejamento. São Carlos: Rima, 2006. p.4559.

CERETTA, M. C. Avaliação dos aspectos da qualidade da água na sub-bacia hidrográfica do Arroio Cadena - município de Santa Maria - RS. 2004. 142f. Dissertação (Mestrado em Engenharia Civil) - Universidade Federal de Santa Maria, Santa Maria, 2004.

EMPRESA BRASILEIRA DE PESQUISA AGROPECUÁRIA - EMBRAPA. Boletins agroclimatológicos. Estação Agroclimatológica de Pelotas $\mathrm{n}^{\circ} 83.984$ (convênio EMBRAPA/UFPel). Disponível em: <http://www.cpact.embrapa.br/agromet/estacao/ index.html>. Acesso em: 29 março 2009.

ESTEVES, F. A. Fundamentos de limnologia. 2. ed. Rio de Janeiro: Interciência, 1998. $602 p$.

GOOGLE EARTH. Disponível em: <http://earth.google.com/intl/pt/>. Acesso em: 20 mar. 2009.

GRÜTZMACHER, D. D.; GRÜTZMACHER, A. D.; AGOSTINETTO, D.; LOECK, A. E.; ROMAN, R.; PEIXOTO, S. P.; ZANELLA, R. Monitoramento de agrotóxicos em dois mananciais hídricos no sul do Brasil. R. Bras. Eng. Agríc. Ambiental, v. 12, n. 6, p. 632-637, 2008.

LEAL, K. S.; BISOGNIN, D. F.; BORBA, L. O.; ROSA, M. C.; MACIEL, L. F.; SANTOS, T. C. O.; GARCIAS, G. L.; MARTINO-ROTH, M. G. Determinação do nível genotóxico do baixo curso do Arroio Pelotas em teste de Allium cepa e Hydrocotyle ranuncoloides. In: CONGRESSO BRASILEIRO DE GENÉTICA, 54., 2008, Salvador. Resumos... Salvador: Sociedade Brasileira de Genética, 2008. Resumo 157. 1 CDROM.

MACÊDO, J. A. B. Águas \& Águas. 2.ed. Belo Horizonte: CRQ-MG, 2004. 977p.

MOLINA, P. M.; HERNANDEZ, F. B. T.; VANZELA, L. S. Índice de qualidade de água na microbacia degradada do Córrego Água da Bomba - município de Regente Feijó - SP. In: CONGRESSO NACIONAL DE IRRIGAÇÃO E DRENAGEM - CONIRD, 26, 2006, Goiânia. Anais... Goiânia, 2006. CD-ROM.

PIEDRAS, S. R. N.; BAGER, A.; MORAES, P. R. R.; ISOLDI, L. A.; FERREIRA, O. G. L.; HEEMANN, C. Macroinvertebrados bentônicos como indicadores de qualidade de água na Barragem Santa Bárbara, Pelotas, RS, Brasil. Ciência Rural, v. 36, n. 2, p. 494-500, 2006. 
CORADI, P. C.; FIA, R., PEREIRA-RAMIREZ, O. Avaliação da qualidade da água superficial dos cursos de água do município de Pelotas-RS, Brasil. Ambi-Agua, Taubaté, v. 4, n. 2, p. 46-56, 2009. (doi:10.4136/ambiagua.85)

PREFEITURA Municipal de Pelotas. Mapa temático: uso do solo. III Plano Diretor. 2006. Disponível em: <http://www.pelotas.com.br/politica_urbana_ambiental/planejamento_ urbano/mapas_municipio/rural_solo.pdf>. Acesso em: 29 março 2009.

REBOUÇAS, A. C. Água Doce no Mundo e no Brasil. In: REBOUÇAS, A. C.; BRAGA, B.; TUNDISI, J. G. (Orgs.). Águas doces no Brasil: capital ecológico, uso e conservação. São Paulo: Escrituras, 1999. 717p.

RIO GRANDE DO SUL. Secretaria do Meio Ambiente. Relatório anual sobre a situação dos recursos hídricos no estado do Rio Grande do Sul. Disponível em: $<$ http://www.sema.rs.gov.br/sema/jsp/rhcomdrh.jsp>. Acesso em: 20 agosto 2008.

RIZZI, N. E. Índices de qualidade de água. Sanare, v. 15, n. 15, p. 11-20, 2001.

SERVIÇO AUTÔNOMO DE SANEAMENTO DE PELOTAS - SANEP. Disponível em: $<$ http://www.pelotas.com.br/sanep>. Acesso em: 23 março 2009.

SILVA, M. G.; GARCIA, C. A. B.; ALVES, J. P. H.; GARCIA, H. L. Qualidade da água da barragem Jacarecica I: estado trófico. In: CONGRESSO DE PESQUISA E INOVAÇÃO DA REDE NORTE NORDESTE DE EDUCAÇÃO TECNOLÓGICA, 1., 2006, Natal. Anais... Natal: IFPA, 2006. 1 CD-ROM.

VON SPERLING, M. Introdução à qualidade das águas e ao tratamento de esgotos. 3.ed. Belo Horizonte: DESA/UFMG, 2005. 452p. (Princípios do tratamento biológico de águas residuárias; 1). 